\title{
Mechanical Failure Mode Causes of In-Wheel Motors
}

\author{
Matej Biček $1,{ }^{*}$ - Gorazd Gotovac ${ }^{1}$ - Damijan Miljavec ${ }^{2}$ - Samo Zupan ${ }^{3}$ \\ 1 Elaphe Propulsion Technologies, Slovenia \\ 2 University of Ljubljana, Faculty of Electrical Engineering, Slovenia \\ 3 University of Ljubljana, Faculty of Mechanical Engineering, Slovenia
}

The presented survey includes a comprehensive overview of mechanical failure mode causes for direct driven electric in-wheel motors. As electric vehicles evolve and develop, in-wheel motor driven vehicles gain acknowledgement, more and more papers are published in order to show individual design challenges and overcoming solutions for failure causes and effects. Obtainable literature is mainly concerned with integral electrical failure modes, neglecting structural causes and effects which in some cases interact. The presented paper inspects the most likely potential mechanical causes of failure modes for in-wheel motors and shows related paper's results for comparison and reference. As several mechanical and electromagnetic layouts and construction topologies exist, only the most promising and generally used one has been studied within this work in order to emphasize sensible directions of further development. Failure mode and effects analysis (FMEA) has been made with severity rating which present mechanical failure potential for permanent magnet synchronous motors intended for in-wheel motor application.

Keywords: in-wheel, failure mode and effects analysis, unsprung mass, excessive vibrations, eccentricity, bearing faults

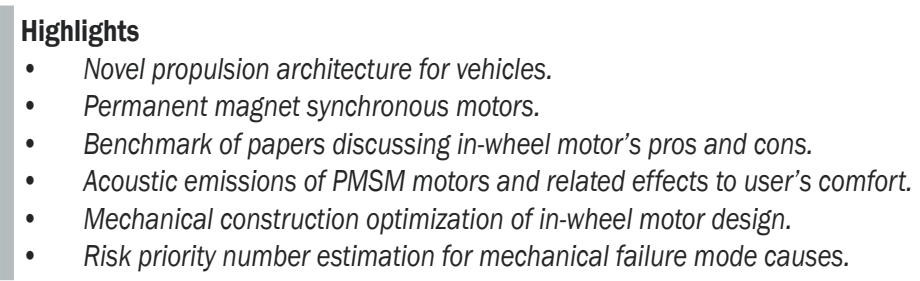

\section{INTRODUCTION}

The International Energy Agency (IEA) has announced that at the end of 2012 about $0.02 \%$ of world's registered vehicles had electric propulsion, including battery electric vehicle (BEV), plug in hybrid electric vehicles (PHEV) and hybrid electric vehicle (HEV). Several scenarios can be obtained for future electric vehicle (EV) global market predictions, mostly dependent on battery's performance to cost ratio. Without any speculations, an objective estimation can be placed where global EV market will reach between 4 and 20 million vehicles, which by then will be equivalent to $0.5 \%$ and respectively $2 \%$ of the global vehicle share [1] to [4].

The future EV should combine the knowledge gained from current vehicles combining passenger safety and comfort aspects, vehicle aerodynamics, weight reduction, low energy consumption and reduced ecological footprint. Electric vehicles meet these requirements at ease, as they have less moving parts and consequently require less maintenance, have much higher efficiency than internal combustion engine (ICE) propulsion, can run on electricity from renewable resources and have no $\mathrm{CO}$ emissions, provide quiet operation and with batteries normally placed under the floor enable better handling characteristics [5] to [7]. The propulsion system architecture within the current EVs does not exploit the versatility of electric motors as they are implemented centrally and maintain the propulsion's transmission and consequently its losses [8]. An in-wheel motor placed inside the rim of two or four wheels exceeds current designs with its holistic approach placing the propulsion system where it is needed, inside the wheel [9]. Direct driven wheels have no losses due to transmission and require no additional space inside the vehicle providing the designers with complete flexibility and freedom to improve passenger's safety, vehicle performance and space. The vehicle's center of gravity becomes lower which in combination with a true torque vectored four-wheel drive significantly improves the drivability of the vehicle [10] and [11].

Consequently, in-wheel motor propulsion systems have a scalable market potential in personal transportation as well as in public usage, ranging from smaller urban vehicles to larger buses and trains [10]. Direct driven vehicles require high specific torque, wide speed range and should be free from maintenance. Permanent magnet synchronous motors (PMSM) with outer rotor and radial electromagnetic flux are among top candidates for such applications 
[12] to [14]. In-wheel motor's electric faults can be found in several surveys and studies. However, a much lesser extent of papers deals with mechanical faults and no paper exists describing interacting impacts of different mechanical faults. The present survey shows a comprehensive overview of permanent magnet synchronous motors (PMSM) motor failure modes with an emphasis on mechanical failures. The scope of this paper covers all potential mechanical fault causes and evaluates their severity objectively, based on measurements and tests performed by different institutions and companies.

\section{GENERAL OVERVIEW OF POTENTIAL IN-WHEEL MOTOR FAILURE MODES}

Safety aspects with fault tolerant control are of major interest in automotive industry [15]. All potential failures should be carefully analyzed and evaluated in the pre-design stage in order to meet automotive standards [16]. It is important to note that the importance of each fault differs, as they have variable probability of occurrence [17]. Safety is largely determined by the ability to cope with unexpected component's overloads without total failure [18]. The failure mode and effects analysis (FMEA) is a procedure in product development, which evaluates risk priority numbers (RPN) for each potential fault. RPN consists of three evaluation parameters: $S$ (severity rating), $O$ (occurrence rating) and $D$ (detection rating) as stated in Eq. (1) [17].

$$
R P N=S \times O \times D,
$$

Severity rating is only partly subjective evaluation, since the standard severity scale from 1 to 10 can be used for evaluation (Table 1).

Table 1. Severity rating [19]

\begin{tabular}{ll}
\hline Rating & Meaning \\
\hline S1 & No effect \\
\hline S2 & Very minor (only noticed by discriminating customers) \\
\hline S3 & $\begin{array}{l}\text { Minor (affects very little of the system, noticed by } \\
\text { average customer) }\end{array}$ \\
\hline S4; S5; S6 & Moderate (most customers are annoyed) \\
\hline S7; S8 & $\begin{array}{l}\text { High (causes a loss of primary function; customers are } \\
\text { dissatisfied) }\end{array}$ \\
\hline S9; S10 & $\begin{array}{l}\text { Very high and hazardous (product becomes } \\
\text { inoperative; customers angered; the failure may result } \\
\text { in unsafe operation and possible injury) }\end{array}$ \\
\hline
\end{tabular}

Occurrence rating is also scaled from 1 to 10 .
Table 2. Occurrence rating [19]

\begin{tabular}{ll}
\hline Rating & Meaning \\
\hline 01 & No failure \\
\hline $02 ; 03$ & Low (relatively few failures) \\
\hline $04 ; 05 ; 06$ & Moderate (occasional failures) \\
\hline $07 ; 08$ & High (repeated failures) \\
\hline $09 ; 010$ & Very high (failure is almost inevitable) \\
\hline
\end{tabular}

And detection rating is also scaled from 1 to 10 .

Table 3. Detection rating [19]

\begin{tabular}{ll}
\hline Rating & Meaning \\
\hline D1 & Almost certain \\
\hline D2 & High \\
\hline D3 & Moderate - noticeable \\
\hline D4; D5; D6 & Moderate - disagreeable or unwanted \\
\hline D7; D8 & Low \\
\hline D9; D10 & Very remote to absolute uncertain \\
\hline
\end{tabular}

A comprehensive overview and objective result evaluation can be a good basis for subjective FMEA evaluation.

The most critical direct drive system failure mode causes include:

Electrical nature of the failure [13], [17] and [20] to [26]:

- Motor winding open circuit, short circuit to housing (ground fault), winding terminal short circuit and internal turn-turn short circuit;

- Power device failures (inverter shuts down, open or short circuit);

- Capacitor failures (open or short circuit);

- Direct current (DC) bus open or short circuit;

- Magnetization faults (uneven magnetization would cause higher torque ripple, lost current in the field weakening range);

- High impedance (broken strand, loose connection);

- Thermal effects (sufficient cooling necessary in order to sustain magnetization and winding insulation.

Mechanical nature of failure:

- Deteriorated driving dynamics when higher unsprung mass is applied [27] to [38];

- Thermomechanical effects (different expansions of materials in assembly and consequential stress - strain state) [13], [30] and [39] to [45];

- Structural elastic deformation due to sudden and unexpected external impacts [15] and [46] to [52];

- Torque pulsation induced vibrations and their impact on acoustics and structure fatigue [53] to [65]; 
- Mechanical failures due to bearing system failure [66] to [68];

- Mechanical failures due to static or dynamic eccentricity [22], [69] and [70];

- Challenges for sealing on high diameter [30] and [71].

Obtainable literature [13], [17] and [20] to [25] has shown in-wheel motor faults in detail from the electrical point of view, in order to understand potential hazards for designing and preventing potential motor malfunction when in operation. Markedly less literature is obtainable regarding potential mechanical malfunctions, irrespective of the fact that some of them are directly connected with electric motors for other applications. As the in-wheel motor is integrated inside the vehicle's rim and usually uses a standard hub bearing from automotive industry, several potential threats need to be envisioned. Fig. 1 shows a simple layout of an in-wheel motor with interchangeable brake elements in exploded view.

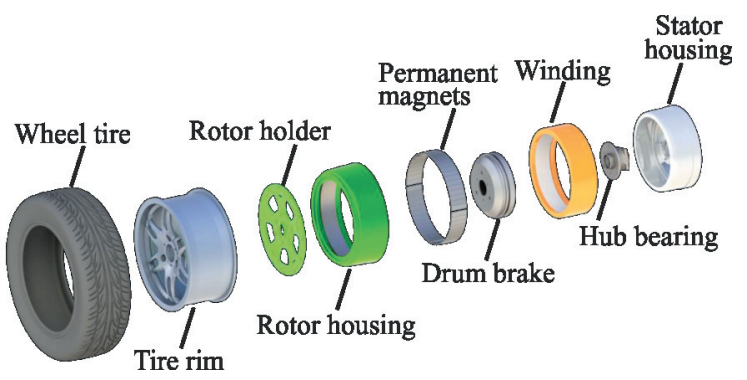

Fig. 1. Elaphe Smart2Gen in exploded view

\section{REVIEW OF MECHANICAL FAULT CAUSES}

As in-wheel motors gain acknowledgement, research papers from commercial and academic literature are frequently published. However, papers and theses consider only the electromagnetic construction design as in [72]. Mechanical fault surveys are mainly oriented to in-wheel motor's effects on driving dynamics via higher unsprung mass, sealing challenges and acoustic emissions and vibrations. The following chapters evaluate published topics, based on their approach, measurements and concluding remarks.

\subsection{Higher Unsprung Mass and Its Impact on Driving Dynamics}

A frequently cited drawback for in-wheel motors is the potential detrimental effect of higher unsprung mass on driving dynamics [12], [27], [30] to [33] and [36]. In the survey [33], different driving scenarios have been investigated by on road experiments with VW Lupo $3 \mathrm{~L}$. The analysis envisioned that two in-wheel motors, each weighting $15 \mathrm{~kg}$, have sufficient performance and can be integrated in front or rear wheels. As the battery pack has been included, the total vehicle mass has been enhanced and also the center of mass has lowered, the ride comfort has actually been improved. The comfort has been measured via the intensity of accelerations of the sprung body and relating them to sensitivity of a human body via ISO 2631-1:1997 [34], [57], [73] and [74]. Even though the ride comfort was allegedly improved, the dynamic wheel load was increased by up to $40 \%$ and the suspension travel up to $16 \%$. Reduction of the tire pressure or usage of an additional vibration absorber is found to be inefficient. In addition, a semi-active and fully active skyhook and hybrid control have been investigated, which both result in final $9 \%$ reduction of dynamic wheel load.

In [27], numerical models and real physical vehicles have been studied for degrading performance and ride comfort. Vehicle performance was divided into ride (ability to absorb disturbances), refinement (ability to attenuate noise and vibration), active safety (stop and steer in emergency cases), driveability (response of the vehicle to steering, braking and drive in normal situations). Each category was subjectively assessed by experts for vehicle dynamics and also objectively assessed via measurements and tests of steering, handling and ride behavior. With subjective results assessment, conclusions were made that the additional unsprung mass equal to $30 \mathrm{~kg}$ in each of the four wheels of Ford Focus 2007 results most notably in heavier steering under a wide circumstance specter. Objective measurements were made with accelerometers applied on different parts of the vehicle and driving over typical UK roads referred to as shake roads. The wheel-hop mode of vibration where the unsprung mass is in motion was reduced from $14 \mathrm{~Hz}$ (conventional vehicle) to $10 \mathrm{~Hz}$ (vehicle with additional unsprung mass in each wheel equivalent to $30 \mathrm{~kg}$ ). This is somewhat reasonable as the additional mass is connected with higher inertias and results in response with less contact and vibration when driving over a barrier. The measured overall ride resulted in perceptible differences with increased unsprung mass. However, they are unlikely to be apparent to an average driver, since they are all within normal boundaries, as noted in the paper. Authors also suggest that the changes can be overcome with standard engineering capabilities and processes which could substantially enhance the vehicle behavior at the final stage [30]. 
In [36], effects on stability, safety and ride comfort of the vehicle were analyzed using a quarter vehicle suspension model. During all simulations, the occurrence of wheel hop phenomena was monitored, which is a function of the unsprung mass and tire stiffness and results in unsprung mass motion relative to vehicle chassis. The survey concludes that the wheel hop is present with in-wheel motors and results with tire needing more time to get back into contact with the surface. The results show potential handling problems at higher vehicle velocities. Despite wheel hop results, the authors conclude that standard suspension of a conventional car can be used for inwheel motor drive vehicles without loss of comfort and safety.

In undergraduate thesis [32], a quarter car model recorded with measured characteristics was simulated. The dynamic system is shown in Fig. 2 with parameters $m_{v}$ being sprung mass, $k_{v}$ spring coefficient with linear characteristics, $d_{d}$ damper relative to speed (measured characteristics), $m_{s}$ stator mass, $m_{r}$ rotor mass (motor rotor + rim + tire), $d_{p}$ tire damping coefficient, $k_{p}$ tire stiffness coefficient.

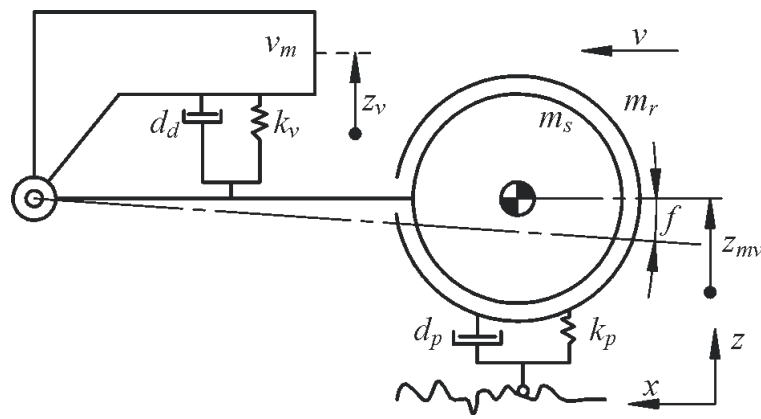

Fig. 2. Quarter car model based on [32]

The entire mechanical system is moving with velocity $v$ and the advantage compared to other quarter vehicle models is that due to the unchanged chassis geometry there is no need for adding corrected spring and damper values and mass can be applied to the rear axle, which is not negligible for the whole system. Different driving scenarios have been considered using multibody dynamics with emphasis on different driving performance and loads for a conventional car and a car with additional $37 \mathrm{~kg}$ of unsprung mass in each rear wheel. Simulations have been carried out for driving over curb-sides with different heights $(100$ and $120 \mathrm{~mm})$ at different speeds $(2,4$ and $8 \mathrm{~km} / \mathrm{h})$, driving over a standard speed bump at different speeds $(15,30$ and $45 \mathrm{~km} / \mathrm{h})$ and over a road pothole (500 mm long and $100 \mathrm{~mm}$ deep) at different speeds $(30,50,70$ and $90 \mathrm{~km} / \mathrm{h})$. Additional studies have been made for vibration isolation and suspension travel ratio, which can be connected with vehicle safety and comfort. Conclusions within this work combine negligible differences for loads on hub bearing when driving over a speed bump and lower accelerations on unsuspended parts, when driving over a curb for all speeds and heights. This can be explained with higher inertias due to higher mass.

Simulating driving over a road pot-hole results also in smaller accelerations when higher unsprung mass is applied and driving with different frequency excitations results in the same way. Accelerations are however higher when the excitation amplitudes and frequencies reach the system's resonant frequencies. Regarding to vibration isolation and the suspension travel ratio, an inconsiderable effect was noticed which shows deterioration. Especially vibration isolation results in lower second eigenfrequency by a factor of two. Eigenfrequency is the motor system's characteristic frequency, at which the system tends to oscillate in the absence of damping. These reductions are closely connected with vehicle suspensions and could be, as noted by the author, largely increased with suspension optimization, such as in [75], where active suspension has been analyzed.

The survey [31] introduces the requirements and stages which were carried out in order to design their electric in-wheel motor, with a brief presentation of the required goals. One crucial in-wheel motor design conflict presented in this survey is the motor weight which must be limited as much as possible to have a small influence of the unsprung mass on dynamic loads and optimized vehicle performance. On the other hand, a motor with a higher mass of active material will have better properties and also passive elements need high stiffness to reduce deformations in the airgap region and maintain motor's electromagnetic performance. Since stiffness and mass are directly connected, a reasonable inflection point should be defined. As noted by the authors, the main concerns with higher unsprung mass being accelerated, are the increased dynamic forces and negative influence towards vehicle dynamics. In order to evaluate these effects, several test drives have been performed with a conventional propulsion and added equivalent to motor masses into rear wheels of a sports car Artega. The complete mass (two motors with $44.2 \mathrm{~kg}$ ) has been divided to static and rotating part in the same way as it is done when the functional motors are mounted on the vehicle. Drive tests have been performed on a test track, which has route sections with different durability relevant sections and maneuvers have been made on all of them. Extensive equipment for 
measuring accelerations, strain gauges and GPS sensors have been implemented on the vehicle and rear wheels. To eliminate the drivers influence on test results, each of the tests has been made with five different drivers with different driving skills. The authors conclude the survey with an increased force amplitude from 0 to $15 \%$ for chassis components and 0 to $25 \%$ for wheel components, decreased wheel hop frequency from 16 to $10 \mathrm{~Hz}$, higher noise when driving over rough road (yet not disturbing) and a more tail-heavy driving characteristic, noticeable as oversteering. As noted in the paper, this is manageable. From the structural durability point of view, however, many other durability tests should be made before a series product can be released.

All surveys conclude that higher dynamic loads are present when additional unsprung mass is incorporated. Although by installing battery packs and setting the vehicle's center of mass lower to the ground, a non-professional driver would most probably not notice any difference in handling, comfort or safety, in fact with true four wheel drive via torque vectoring, the driving experience should even be improved [76]. Three most comprehensive papers [27], [31] and [33] conclude that the negative effects of feeling a tail-heavy rear should be resolved with suspension balancing, the ride comfort should not be reduced and the dynamic loads are increased from 15 to $40 \%$.

\subsection{Eccentricity}

For rotary dynamics, eccentricity is an important durability factor and, as such, should be discussed in detail. Static and dynamic eccentricity result in different ways and due to finite tolerances within production technologies, eccentricity is present in every mechanical design [22] and [70]. Static radial eccentricity can be described with shifted axes of rotor to stator, as a consequence of mounting errors or inaccuracies when producing positioning flanges. Radial dynamic eccentricity can be described as rotor's center misaligned with the axis of rotation [77]. Both eccentricities mainly result from dimensional and geometrical inaccuracies when producing elements and are always present to some extent as is the accuracy of production. As shown in Fig. 3, eccentricities deform the air gap in different ways and both have an additional impact on induced radial forces due to motor's changed magnetic flux.

Static axial eccentricity is present when a rotor rotates around its natural axis that is inclined compared to the stator one and dynamic axial eccentricity is present when rotor's natural axis is inclined to its rotational [22]. Both axial eccentricities can be achieved with inaccurate machining operations and positioning accuracy when assembling parts. As shown in Fig. 4, axial eccentricities have similar effects on the deformed air gap and are mainly dependent on inclination angle and axial motor length.

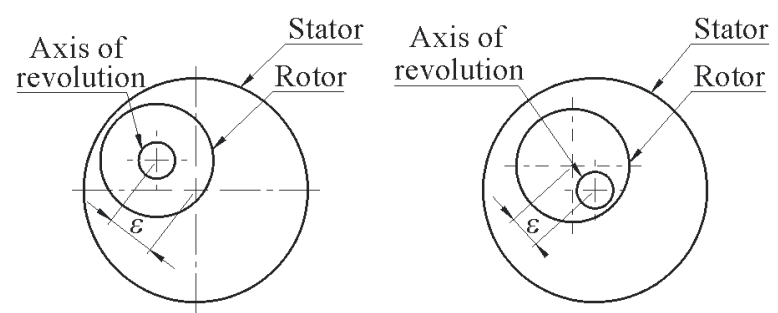

Static radial eccentricity Dynamic radial eccentricity

Fig. 3. Static and dynamic radial eccentricity [77]

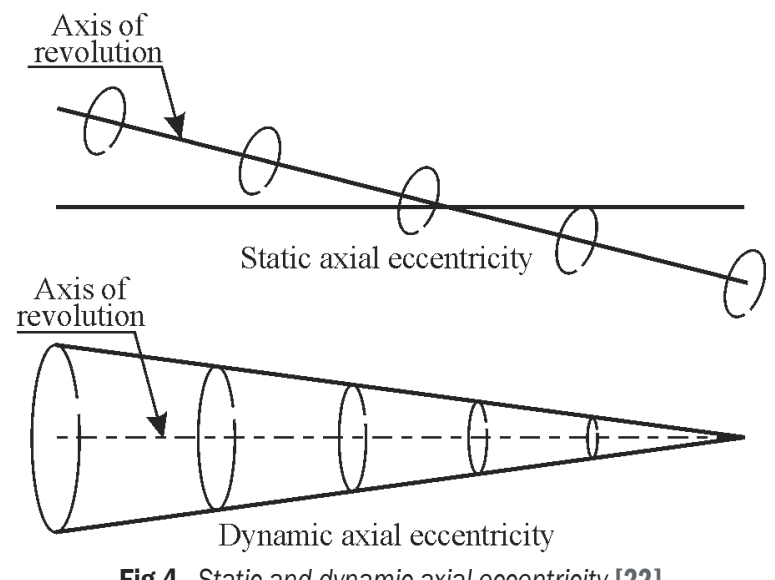

Fig.4. Static and dynamic axial eccentricity [22]

All eccentricities result in higher radial forces due to uneven magnetic fields, which was analyzed in [38] and [68]. It can also have an impact on winding failure, induced vibrations or consequently lead to premature bearing failure [70].

In-wheel motors are designed with a nominal air gap, between stator lamination and rotor magnets, normally dimensioned to $1 \mathrm{~mm}$ in order to minimize reluctance in the magnetic flux path [12]. When eccentricity of the motor is present, a non-uniform air gap occurs, consequently leading to uneven electromagnetic force distribution around the circumference. As discussed in the survey [68], the force due to eccentricity can be calculated via the electromagnetic energy in the magnetic air gap, which is directly connected to its thickness [65]. Results of analytical calculations were verified numerically using finite element based software for a $450 \mathrm{Nm}$ direct drive in-wheel motor. The whole machine was modeled, including the appropriate materials. The 
force was calculated for a stationary case, where there is no current in the winding. The numerical calculation was performed for discrete values of eccentricity $\varepsilon$ ranging from 0 to $0.7 \mathrm{~mm}$. The results and comparison to the analytical calculation are shown in Fig. 5.

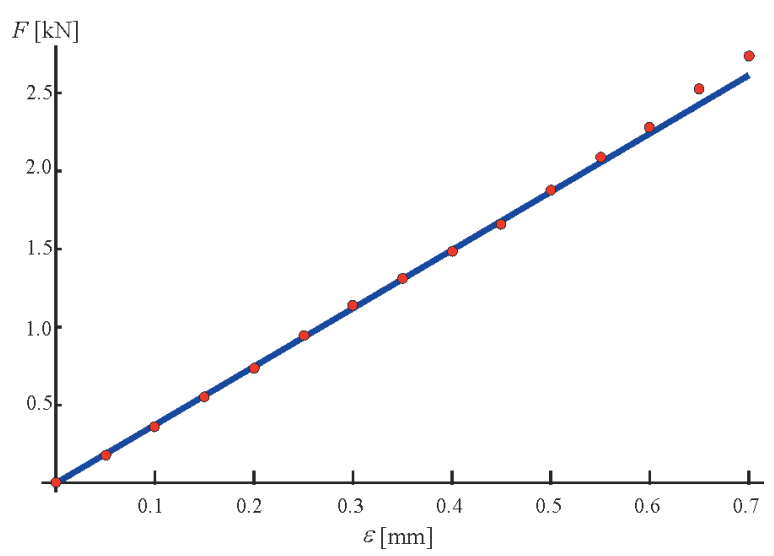

Fig. 5. Comparison of values for the analytical force calculation (solid line) and the FEM based calculations (points) [68]

The calculation was also made for a fully electromagnetically loaded motor, but no relevant increase of radial force occurs. The analysis of the additional radial forces shows that although the eccentricity of $0.1 \mathrm{~mm}$ is deemed within acceptable limits, it yields an additional radial force of $350 \mathrm{~N}$. If the eccentricity is larger, due to an unexpected fault, the value of the force rises to $1.1 \mathrm{kN}$ for $0.3 \mathrm{~mm}$ and $1.9 \mathrm{kN}$ for $0.5 \mathrm{~mm}$ of eccentricity. Survey [38] used a similar approach for calculating the additional radial force, due to electromagnetism when eccentricity is applied. The conclusion of this survey shows that $0.1 \mathrm{~mm}$ of eccentricity corresponds to $500 \mathrm{~N}$ of additional radial force and at $0.5 \mathrm{~mm}$ the additional force is $550 \mathrm{~N}$. Calculations from different surveys vary as the motor electromagnetic topologies differs and results in different electromagnetic fluxes. Eccentricity and bearing faults are connected via vibrations in both directions. When one occurs, the other is a consequence [23]. Based on [38] and [68], $0.1 \mathrm{~mm}$ of eccentricity can result in approximately 350 to $500 \mathrm{~N}$ of additional radial force for PMSM outer rotor motors, due to changed electromagnetic flux density.

Dynamic eccentricity is normally eliminated with balancing, while static needs to be envisioned when designing static and rotating components [77]. However, in case balancing has not been resolved as required, an additional centrifugal force should be expected as shown on Fig. 6. Applied centrifugal force has been calculated for rotor diameter from Table 4 and maximum velocity.

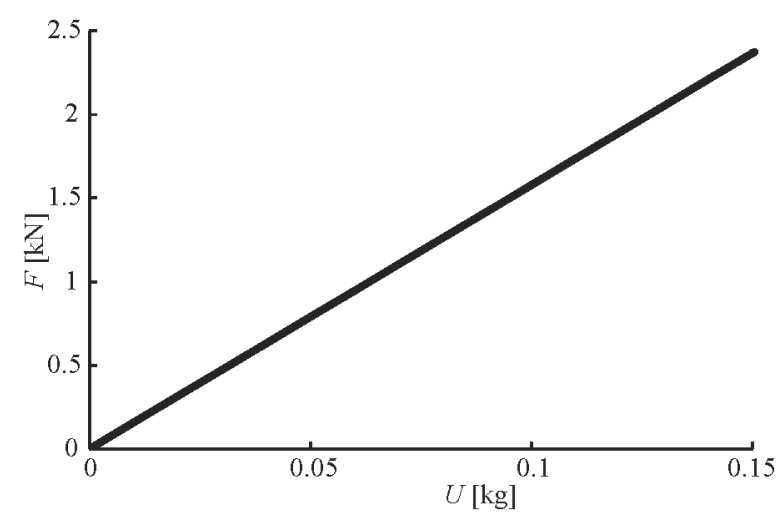

Fig. 6. Additional radial centrifugal force due to eccentricity

Figs. 5 and 6 show additional radial forces which need to be taken into account with PMSM motors when eccentricity $(\varepsilon)$ and unbalance $(U)$ is applied. Resulting forces have been calculated for in-wheel motor with specifications shown in Table 4.

Table 4. In-wheel motor specifications

\begin{tabular}{lcr}
\hline Peak torque & {$[\mathrm{Nm}]$} & 700 \\
\hline Continuous torque & {$[\mathrm{Nm}]$} & 450 \\
\hline Peak power & {$[\mathrm{kW}]$} & 75 \\
\hline Constant power & {$[\mathrm{kW}]$} & 50 \\
\hline DC supply voltage & {$[\mathrm{V}]$} & 96 \\
\hline DC supply current & {$[\mathrm{A}]$} & 500 \\
\hline Axial width & {$[\mathrm{mm}]$} & 130 \\
\hline Radial diameter & {$[\mathrm{mm}]$} & 360 \\
\hline Maximum speed & {$[\mathrm{rpm}]$} & 1500 \\
\hline $\begin{array}{l}\text { Motor mass - electromagnetic active } \\
\text { (magnets, iron, steel blades, copper winding) parts }\end{array}$ & {$[\mathrm{kg}]$} & 13 \\
\hline $\begin{array}{l}\text { Motor mass - electromagnetic passive (Al housing } \\
\text { for rotor and stator, cooling system) parts }\end{array}$ & {$[\mathrm{kg}]$} & 11 \\
\hline $\begin{array}{l}\text { Parts from the original propulsion } \\
\text { (hub bearing, drum brake with anchor plate) }\end{array}$ & {$[\mathrm{kg}]$} & 7 \\
\hline
\end{tabular}

Eccentricity is one of the most common mechanical fault causes within rotational devices and should be resolved with caution [23]. As described above, PMSM devices have two side effects when eccentricity occurs, one is additional radial force due to changed magnet flux and the other is additional force due to inertia.

\subsection{Sealing of In-Wheel Motors}

Sealing failure is not a direct motor-failure mode cause, but its design must be considered carefully in order to avoid inducing other mechanical faults. In- 
wheel motor's layout can have internal or external rotor, both layouts have its own pros and cons. Internal rotor motors can have simmering sealing, which is reliable, cost efficient and generates low braking torque. External rotor motors have a higher diameter of air gap and consequently higher specific torque, which makes them a better choice for vehicle propulsion application. On the other hand, they require seals of higher diameter, which can generate higher braking torques or result in unreliable sealing [12], [31] and [76]. As noted in [30], sealing for in-wheel motors was resolved with a combination of different materials, offering complete protection against water and particle ingress, with the possibility of allowing condensation and moisture release. A V lip is used in this design for water and particle ingress protection, while all electronic parts are potted with epoxy resin providing IP 68 rating. Additional hydrophobic gel is applied on electronics to avoid damage during any submerging situations. It is apparent from [76] that a successful sealing unit was developed, which can withstand high circumferential velocities $(30 \mathrm{~m} / \mathrm{s})$ and prevents ingress of contaminants during operation and standstill.

\section{Vibration and Noise}

Permanent magnet synchronous motors are known for emitting low noise in comparison with other types of motors for similar applications [55]. Noise of operation originates from vibrations due to mechanical (bearing defects and mounting accuracy, loads, rotor and shaft misalignment), electromagnetic (excited magnetic flux density waves in the air gap, caused by the slot geometry, distribution of winding in slots, input current waveform distortion, air gap permeance fluctuations, rotor eccentricity, phase unbalance all resulting in torque pulsation) and aerodynamic sources (obstacles placed in the air stream [53] and [55]. Vibrations arising from the above causes can vary from an almost soundless to unwanted loud noise, which indicates a certain motor failure. With predictive design and FEM based modal analyses, it is possible to identify the root cause of vibration problems, caused by motor's geometry and more significantly eliminate or reduce most problems in the design stage [78]. With a rational electromagnetic design of a PMSM motor, the torque pulsation can be minimized and designing a rotor with proper stiffness results in low noise when operating. Torque pulsation sources can be divided to cogging effects, distortion of sinusoidal distribution of the magnetic flux inside the air gap and as the difference between permeance of the air gap. Cogging frequency, which is in most literature represented as the most problematic, can be calculated using Eq. (2) [12], [65] and [72]. When designing rotor elements, geometry eigenfrequencies should be taken into consideration, controlled and if possible, any overlapping cogging and eigen-frequencies should be avoided [53].

$$
f_{c}=s_{1} n_{s}=s_{1} \frac{f}{p}
$$

where $s_{1}$ is the number of stator slots, $n_{s}=f / p$ is the synchronous speed, $p$ is the number of pole pairs and $f$ is the input electrical frequency. Since direct driven vehicles have no gears, $n_{s}$ is normally in the range 0 to $1200 \mathrm{rpm}$, relative to tire size selection and desired vehicle top speed. Consequential cogging frequency depends on the EM motor design, such as the number of slots and their geometry. If the first eigenmodes are designed to have a higher value than cogging frequency, less vibration should occur when operating [56].

Further development should integrate vibrational fatigue tests for random loads the motor is subjected to during operation, such as stated in [60] where a numerical fatigue prediction model has been compared to experimental tests in order to verify its accuracy. The damping loss factor percent has been defined within this survey for proper high cycle fatigue life estimations of dynamic structures.

\subsection{Bearing Related Faults}

According to [21], [25] and [70], 40 to $50 \%$ of all motor failures are bearing related and they are certainly more likely to occur when higher than normal loads are applied. Automotive hub bearings are one of the most important elements for vehicle dynamics, sustaining performance and maintaining safety. Bearings are designed to withstand various sets of loads, while providing minimal rotational resistance in a long lifespan. The latter is dependent on several factors, such as sealing, lubrication, cleanliness, material properties, machining and mounting accuracy, system stiffness and axial/radial load quantities [79]. Hub bearing loads are successfully managed in mass produced vehicles, but should be considered when integrated into an in-wheel motor, due to possible impacts from higher wheel mass [76].

Motor's internal vibrations, eccentricity and premature bearing failure are in relation with each other and simultaneously open new categories of potential motor failures if not resolved in time.

Hypothetical combinations of static eccentricities and unsprung mass effects are discussed in [68], where 
a reasonable eccentricity equal to $0.1 \mathrm{~mm}$ and $40 \%$ increase in dynamic loads due to higher unsprung mass result in $31 \%$ life reduction for a standard hub bearing used in a urban vehicle.

\section{FAILURE MODE CAUSES}

Failure mode and effects analysis is normally held as several meetings of highly skilled individuals who mostly participate in the design or process stage of a project in several iterations. The highest possible result objectiveness is sought-after and in this way the impact of an individual opinion is reduced [17]. FMEA is a subjective assessment tool, which uses a qualitative approach to identify potential failure modes, their causes and effects for design, manufacture and operation stages [23]. Table 5 shows the results of the analysis made corresponding to the studied and cited obtainable literature. In general, high severity was rated only for faults which are presented as continuous or problematic in obtainable literature. Severity of failure modes can easily be extrapolated from the obtained analyses. However, occurrence and detection can only be previsioned, since in wheel motors exist only for testing and showcase purposes.
In relation to the known parameters of permanent magnet motors with high pole numbers used for other applications, analogies have been made. Mechanical faults such as vibrations and eccentricity have described the occurrence rating in [23]. Detection rating was envisioned based on findings in review articles such as [87] to [89].

\section{CONCLUSION}

The presented survey examines mechanical failure mode causes for electric in-wheel motors intended for propulsion systems of purely electric or hybrid vehicles. Within the scope of research, emphasis was made on frequently cited topics, such as application of higher unsprung mass and its effects on potentially deteriorated driving dynamics. In addition, failure mode causes such as static and dynamic eccentricity, excessive vibrations and consequential noise, reduced hub bearing lifetime and sealing challenges have also been examined in obtainable literature in order to be addressed with severity. This was used to establish an overview failure mode and effects analysis covering all the mechanical failure mode causes known for rotational devices, with emphasis on direct driven

Table 5. Mechanical failure mode causes for PMSM in-wheel motors

\begin{tabular}{|c|c|c|c|c|c|c|c|}
\hline 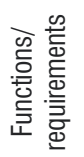 & 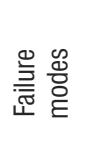 & $\begin{array}{l}\text { Failure mode } \\
\text { causes }\end{array}$ & Potential failure mode effect & $\begin{array}{l}\text { Severity based on } \\
\text { literature }\end{array}$ & $\begin{array}{l}\text { Previsioned occurrence } \\
\text { and detection ratings }\end{array}$ & $\begin{array}{l}\text { RPN } \\
\text { rate }\end{array}$ & Ref. \\
\hline \multirow{11}{*}{ 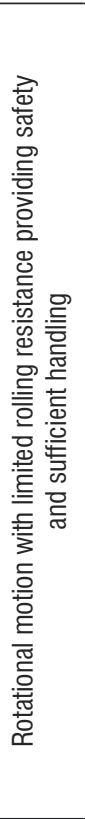 } & \multirow{11}{*}{ 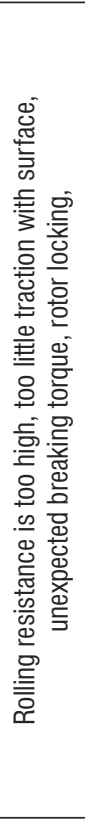 } & \multirow{3}{*}{$\begin{array}{l}\text { Higher } \\
\text { unsprung } \\
\text { mass }\end{array}$} & Deteriorated driving comfort & Very minor (S2) & $\begin{array}{l}\text { High occurrence (07) } \\
\text { Moderate detection (D3) }\end{array}$ & 42 & \multirow{3}{*}{ [27] to [38] } \\
\hline & & & Induced dynamic loads & Minor (S3) & $\begin{array}{l}\text { Low occurrence (03) } \\
\text { Low detection (D6) }\end{array}$ & 54 & \\
\hline & & & Tail-heavy effect & Moderate (S5) & $\begin{array}{l}\text { Moderate occurrence (04) } \\
\text { High detection (D2) }\end{array}$ & 40 & \\
\hline & & \multirow{2}{*}{ Eccentricity } & Reduced durability & Very minor (S2) & $\begin{array}{l}\text { High occurrence (07) } \\
\text { Low detection (D6) }\end{array}$ & 84 & $\begin{array}{c}\text { [22], [23], [53], } \\
\text { [69], [70] }\end{array}$ \\
\hline & & & High noise & Moderate (S6) & $\begin{array}{l}\text { High occurrence (07) } \\
\text { Moderate detection (D3) }\end{array}$ & 126 & [77] \\
\hline & & \multirow{2}{*}{$\begin{array}{l}\text { Excessive } \\
\text { vibrations }\end{array}$} & Reduced durability & Very minor (S2) & $\begin{array}{l}\text { High occurrence (07) } \\
\text { Low detection (D6) }\end{array}$ & 84 & $\begin{array}{l}{[59],[60],} \\
{[80],[81]}\end{array}$ \\
\hline & & & High noise & Moderate (S6) & $\begin{array}{l}\text { High occurrence (07) } \\
\text { Moderate detection (D3) }\end{array}$ & 126 & $\begin{array}{l}\text { [55], [82], } \\
{[83],[84]}\end{array}$ \\
\hline & & \multirow{3}{*}{$\begin{array}{l}\text { Insufficient } \\
\text { sealing }\end{array}$} & $\begin{array}{l}\text { Unexpected braking torque due } \\
\text { to mechanical contaminants }\end{array}$ & High (S7) & $\begin{array}{l}\text { Remote occurrence (01) } \\
\text { Low detection (D6) }\end{array}$ & 42 & \multirow{3}{*}{ [30], [31], [76] } \\
\hline & & & $\begin{array}{l}\text { High voltage on chassis due to } \\
\text { conductive liquid in the air gap }\end{array}$ & High (S7) & $\begin{array}{l}\text { Remote occurrence (01) } \\
\text { Low detection } \mathrm{D}(6)\end{array}$ & 42 & \\
\hline & & & Reduced durability & Minor (S3) & $\begin{array}{l}\text { Low occurrence (2) } \\
\text { Low detection (6) }\end{array}$ & 36 & \\
\hline & & Bearing failure & Vehicle stability reduction & High (S8) & $\begin{array}{l}\text { High occurrence (08) } \\
\text { Moderate detection (D3) }\end{array}$ & 192 & $\begin{array}{c}\text { [54], [68], [69], } \\
{[85],[86]}\end{array}$ \\
\hline
\end{tabular}


outer rotor PMSM in-wheel motors. Within the FMEA, a comprehensive benchmark of risk potentials for individual mechanical failure mode causes has been determined via risk priority numbers.

\subsection{Main Surveys's Findings}

Surprisingly, the most cited mechanical fault, higher unsprung mass effects on deteriorated driving dynamics, achieves one of the lowest risk potentials, based on all objective surveys. Sealing challenges, which are also frequently cited as very problematic, seem to be solved and do not present a high risk potential. Vibrations with consequential acoustic emissions and static/dynamic eccentricity result in highest risk potential as their interactions with other failure mode causes were taken into account. Within mature applications, rotational device designs have been successfully managed towards eliminating vibrations and eccentricity. As PMSM motors for in-wheel propulsion application are currently under testing and development, all of the presented mechanical faults should be considered in a novel design.

\subsection{Evaluation of RPN Ratings for Mechanical Mode Causes}

Since individual failure mode causes have a different number of failure effects, they should be summed up in order to show the most problematic mechanical ones. Based on the existing literature and analyses made for motors for another applications, extrapolation was made for determining the most problematic mechanical causes.

They are presented in Table 6 in relation to the achieved maximum rating priority numbers.

Table 6. RPN ratings for most likely mechanical failure causes

\begin{tabular}{lc}
\hline Mechanical failure mode case & Evaluated RPN ratings \\
\hline Higher unsprung mass & 126 \\
\hline Eccentricity & 210 \\
\hline Excessive vibrations & 210 \\
\hline Insufficient sealing & 120 \\
\hline Bearing failure & 192 \\
\hline
\end{tabular}

As evident from the results obtained, the mainly cited failure causes do not represent threats and are manageable, based on the obtained literature. Standard design faults for rotational devices reach higher risk ratings and should be considered, e.g. hub bearing deflection angle should be reduced in comparison to standard original equipment manufacturer's (OEM) products for current automotive industry. Similar examples are eccentricity and vibrations, which interact with motor's electromagnetic properties and have a more significant effect on the product's safety, durability and overall performance.

\section{FURTHER WORK}

The authors have made a complete review of published literature regarding in-wheel motor's electromagnetic and mechanical design. Within the research, several deficiencies have been observed from the mechanical design perspective as no FMEA analysis for mechanical faults is obtainable, neither is a structural optimization methodology for a stochastically loaded construction, which should preserve low mass and high stiffness. Further work should be aimed at thermo-mechanical analyses and structural deformations due to sudden impacts, which are much more complex, yet necessary for complete failure mode evaluation of a product that could reach series production in automotive industry.

\section{REFERENCES}

[1] International Energy Agency - Electric Vehicle Initiative and Clean Eenergy Ministerial. Global EV Outlook - Understanding the Electric Vehicle Landscape to 2020, from http://www.iea. org/publications, accessed on 2014-10-05.

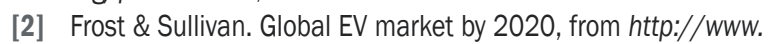
thegreenautomotivecompany.com, accessed on 2014-10-05.

[3] Nemry, F., Brons, M. (2011). Market Penetration Scenarios of Electric Drive Vehicles. Institute for Prospective Technological Studies, Seville.

[4] Balducci, P.J. (2010). Plug-in Hybrid Electric Vehicle Market Penetration Scenarios. US Department of Energy - Pacific National Laboratory, Springfield.

[5] Khusid, M. (2010). Potential of Electric Propulsion Systems to Reduce Petroleum Use and Greenhouse Gas Emissions in the U. S. Light-Duty Vehicle Fleet. Massachusets Institute of Technology, Massachusets

[6] Geissinger, J.M. (2012). The future powertrain - challenge between internal combustion engine and electric mobility. 33rd International Vienna Motor Symposium, p. 22-37.

[7] Kulkarni, A., Kapoor, A., Ektesabi, M., Lovatt, H. (2012). Electric vehicle propulsion system design. Sustainable Automotive Technologies, vol. 61, no. 03, p. 199-206, D0l:10.1007/9783-642-24145-1_26.

[8] Lampič, G., Slivnik, T., Detela, A. (2005). Holistic approach in developing propulsion system for urban electric vehicles. Vehicle Power and Propulsion Conference Proceedings, $\mathrm{p}$. 268-272, DOI:10.1109/VPPC.2005.1554569.

[9] Lampič, G. (2006). Analysis of the Deployment of Electric Drives in Various Types of Vehicles and Drive Design for the 
Modern Urban Electric Hybrid Car. University of Ljubljana, Faculty of Electrical Engineering, Ljubljana. (in Slovene)

[10] Heim, R., El Dsoki, C. Hanselka, H. (2012). Technical potential of in-wheel motors, ATZ, vol. 114, no. 10, p. 4-9.

[11] Fraser, A. (2011). In-wheel electric motors. 10th International CTI Symposium, p. 12-23.

[12] Hooper, I. (2011). Development of In-Wheel Motor Systems for Formula SAE Electric Vehicles. University of Western Australia, Perth.

[13] Pérez, S.R. (2011). Analysis of a Light Permanent Magnet InWheel Motor for an Electric Vehicle With Autonomous Corner Modules. Royal Institute of Technology, Stockholm.

[14] Rasmussen, P.O., Matzen, T.N. (2009). Torque Control in Field Weakening Mode. Institute of Energy Technology, Aalborg.

[15] Heyes, A.M. (1998). Automotive component failures. Engineering Failure Analysis, vol. 5, no. 2, p. 129-144, DOI:10.1016/S1350-6307(98)00010-7.

[16] ISO 6469-2:2009 (2009). Electric Road Vehicles - Safety Specifications - Part 2: Functional Safety Means and Protection Against Failures. International Organization for Standardization, Geneva.

[17] Liao, Y. (2011). Analysis of Fault Conditions in PermanentMagnet In-Wheel Motors. Royal Institute of Technology, Stockholm.

[18] Grubišić, V., Fischer, G. (1997). Methodology for effective design evaluation and durability approval of car suspension components. SAE. SAE technical paper 970094, DOI:10.4271/970094.

[19] Jonas, P., Karlberg, M. (1997). Variation mode and effect analysis compared to FTA and FMEA in product development. ASME Design Engineering Technical Conference, p. 252-260.

[20] Ifedi, C.J., Mecrow, B.C., Brockway, S.T.M., Boast, G.S., Atkinson, G.J., Kostic-Perovic, D. (2011). Fault tolerant inwheel motor topologies for high performance electric vehicles. IEEE Electric Machines \& Drives Conference, p. 1310-1315, DOI:10.1109/IEMDC.2011.5994794.

[21] Wang, R., Wang, J. (2011). Fault-tolerant control with active fault diagnosis for four-wheel independently driven electric ground vehicles. IEEE Transactions on Vehicular Technology, vol. 60, no. 9, p. 4276-4287, D0I:10.1109/TVT.2011.2172822.

[22] Ghoggal, A., Zouzou, E.S., Razik, R., Sahraoui, M., Khezzar, A. (2009). An improved model of induction motors for diagnosis purposes - slot skewing effect and air-gap eccentricity faults. Energy Conversion Management, vol. 50, no. 5, p. 13361347, D0l:10.1016/j.enconman.2009.01.003.

[23] Tavner, J.P., Ran, L., Sedding, H. (2008). Review of Condition Monitoring of Rotating Electrical Machines. The Institution of Engineering and Technology, London, Dol:10.1049/ietepa:20070280.

[24] Jonasson, M., Wallmark, O. (2007). Stability of an electric vehicle with permanent-magnet in-wheel motors during electrical faults. World Electric Vehicle Association Journal, vol. 1, no. 4, p. 100-107.

[25] Muenchof, M., Beck, M., Isermann, R. (2009). Fault -tolerant actuators and drives-structures, fault detection principles and applications. Annual Reviews in Control, vol. 33, no. 2, p. 136148, D0I:10.1016/j.arcontrol.2009.08.002.
[26] Liu, X., He, H., Xiong, R., Qian, T. (2012). Study on the fault tolerance control strategy of the distributed driving electric vehicle running in straight line with failure motor(s). $2^{\text {nd }}$ International Conference on Electronic \& Mechanical Engineering and Information Technology, p. 1627-1632.

[27] Anderson, M., Harty, D. (2010). Unsprung mass with in-wheel motors - myths and realities. AVEC 2010, p. 261-266.

[28] Purdy, D.J., Simner, D. (2004). A brief investigation into the effect on suspension motions of high unsprung mass. Journal of Battlefield Technology, vol. 7, no. 1, p. 15-20.

[29] Nagaya, G., Wakao, Y., Abe, A. (2003). Development of an in-wheel drive with advanced dynamic-damper mechanism. JSAE Review, vol. 24, no. 4, p. 477-481, D0I:10.1016/\$03894304(03)00077-8.

[30] Perovic, D.K. (2012). Making the impossible, possible overcoming the design challenges of in wheel motors. EVS 26, p. 48-58.

[31] Kasgen, J., Heim, R. (2013). Product Development \& Testing Requirements for Fraunhofer E-Concept Car - Frecc0. Fraunhofer LBF, Darmstadt.

[32] Trček, T. (2013). The Impact of the Increased Weight of the Wheel Assembly on the Vertical Dynamics of a Vehicle and on the Forces of the Wheel Bearing. University of Ljubljana Faculty of Mechanical Engineering, Ljubljana. (in Slovene)

[33] Vos, R. (2010). Influence of In-Wheel Motors on the Ride Comfort of Electric Vehicles. Eindhoven University of Technology, Eindhoven.

[34] Wong, J.Y. (2001). Theory of Ground Vehicle. John Wiley \& sons, New York.

[35] Siddiqui, 0.M. (2002). Dynamic Analysis of a Modern Urban Bus for Assessment of Ride Quality and Dynamic Wheel Loads. Concordia University, Concordia.

[36] van Schalkwyk, D.J., Kamper, M.J. (2006). Effect of hub motor mass on stability and comfort of electric vehicles. IEEE Vehicular Power Propulsion Conference, vol. 4, no. 1, p. 1-6, DOI:10.1109/VPPC.2006.364297.

[37] Bruder, T. (2011). An Insight into Fraunhofer System Research for Electromobility. German - American Chambers of Commerce, p. 1-24.

[38] Luo, Y., Tan, D. (2012). Study on the dynamics of the in-wheel motor system. IEEE Transactions on Vehicular Technology, vol. 61, no. 8, p. 3510-3518, D0I:10.1109/TVT.2012.2207414.

[39] Belhocine, A., Bouchetara, M. (2013). Investigation of temperature and thermal stress in ventialted disc brake based on 3D thermomechanical coupling model. Ain Shams Engineering Journal, vol. 4, no. 1 p. 475-483, Dol:10.1016/j. asej.2012.08.005.

[40] Jayaprakash, G., Sivakumar, K., Thilak, M. (2011). Integration of thermo mechanical strains into optimal tolerance design of mechanical assembly using NSGA II and FE simulations. Journal of Mechanical Engineering Research, vol. 3, no. 6, p. 168-180.

[41] Kuria, J., Hwang, P. (2011). Optimizing heat sink geometry for electric vehicle BLDC motor using CFD. Sustaniable Research and Innovation Proceedings, vol. 3, p. 122-146.

[42] Camilleri, R., Howey, D.A., McCulloch, M.D. (2012). Thermal limitations in air-cooled in-wheel motors for urban mobility 
vehicles. Electrical Systems for Aircraft, Railway and Ship Propulsion, p. 48-60, D0I:10.1109/ESARS.2012.6387494.

[43] Bennion, K. (2011). Electric Motor Thermal Management. US Department of Energy, Washington, D.C.

[44] Yanhua, S., Chun, J. (2011). Thermal behavior of pm inwheel motor used in off-road motor driven truck. Procedia Engineering Conference, vol. 23, p. 222-228, D0l:10.1016/j. proeng.2011.11.2493.

[45] Markovic, M., Muller, V., Hodder, A., Perriard, Y. (2010). Optimal design of an in-wheel BLDC motor for a kick scooter. 2010 IEEE Energy Conversion Congress and Exposition, p. 292-296, DOI:10.1109/ECCE.2010.5618023.

[46] Cebon, D., Winkler, C. (1991). A Study of Road Damage Due to Dynamic Wheel Loads Using a Load Measuring Material. University of Cambridge, Department of Engineering, Cambridge.

[47] Gallagher, R.H. (1973). Optimum Structural Design: Theory and Applications. John Wiley \& Sons, New York.

[48] Zienkiewicz, O.C., Campbell, J.S. (1973). Shape Optimization and Sequential Linear Programming - Optimum Structural Design Theory and Applications. John Wiley \& Sons, New York.

[49] Kirsch, U. (1993). Structural Optimization: Fundamentals and Applications. Springer, Berlin, Dol:10.1007/978-3-642-848452.

[50] Gajewski, A., Zyczkowski, M. (1988). Problems of Optimal Structural Design. Springer Science+Business Media B.V., Dordrecht.

[51] Cakir, K., Sabanovic, A. (2006). In-wheel motor design for electric vehicles. 9th IEEE International Workshop on Advanced Motion Control, p. 613-618, D0I:10.1109/AMC.2006.1631730.

[52] Triche, E.J.J., Beno, J.H., Tims, H.E., Worthington, M.T., Mock, J.R. (2005). Shock Loading experiments and requirements for electric wheel motors on military vehicles, SAE World Congress \& Exhibition, DOI:10.4271/2005-01-0278.

[53] Gieras, J.F., Wang, C., Lai, J.C. (2006). Noise of Polyphase Electric Motors. Taylor \& Francis Group, Columbus.

[54] Rubio, E., Jáuregui, J.C. (2012). Experimental characterization of mechanical vibrations and acoustical noise generated by defective automotive wheel hub bearings. Procedia Engineering Conference, vol. 35, p. 176-181, D0l:10.1016/j. proeng.2012.04.178.

[55] Lakshmikanth, S., Natraj, K.R., Rekha, K.R. (2012). Noise and vibration reduction in PMSMs. International Journal of Electrical and Computer Engineering, vol. 2, no. 3, p. 405-416.

[56] Lee, S., Hong, J., Member, S., Hwang, S., Lee, W., Lee, J., Kim, Y. (2006). Optimal design for noise reduction in interior permanent-magnet motor. 41st IAS Annual Meeting, p. 19541960.

[57] Griffin, M.J. (2007). Discomfort from feeling vehicle vibration. International Journal of Vehicle Mechanics and Mobility, vol. 45, no. 7-8, p. 679-698, DOl:10.1080/00423110701422426.

[58] Hostettler, R. (2012). Vehicle Parameter Estimation Using Road Surface Vibrations. Lulea University of Technology, Lulea.

[59] Kelly, S. G. (2012). Mechanical Vibration - Theroy and Applications. Cengage Learning, Stamford.

[60] Česnik, M., Slavič, J. (2014). Vibrational fatigue and structural dynamics for harmonic and random loads. Strojniški vestnik
- Journal of. Mechanical Engineering, vol. 60, no. 5, p. 339348, D0I:10.5545/sv-jme.2014.1831.

[61] Gobbi, M., Mastinu, G. (1998). Expected fatigue damage of road vehicles due to road excitation. Vehicular. System Dynamics: International Journal of Vehicular Mechanical Mobility, vol. 29, suppl. 1, p. 778-788, D0l:10.1080/00423119808969608.

[62] SAE J 2562 (2005). Biaxial Wheel Fatigue Test. Society of Automotive Engineers International, Warrendale.

[63] Fatemi, A., Vangt, L. (1998). Cumulative fatigue damage and life prediction theories: a survey of the state of the art for homogeneous materials. International Journal of Fatigue, vol. 20, no. 1, p. 9-34, Dol:10.1016/S0142-1123(97)00081-9.

[64] Sonsino, C. (2007). Fatigue testing under variable amplitude loading. International Journal of Fatigue, vol. 29, no. 6, p. 1080-1089, D0I:10.1016/j.ijfatigue.2006.10.011.

[65] Abbaszadeh, K., Rezaee Alam, F., Saied, S.A. (2011). Cogging torque optimization in surface-mounted permanent-magnet motors by using design of experiment. Energy Conversation Management, vol. 52, no. 10, p. 3075-3082, D0l:10.1016/j. enconman.2011.04.009.

[66] Harris, T.A., Kotzalas, M.N. (2007). Essential Concepts of Bearing Technology. Taylor \& Francis, Boca Raton.

[67] Heim, R., Zinke, R., Klock, J. (2006). Experimental Testing of Wheel Bearings - Operating Load Simulation in the Biaxial Wheel / Hub Bench, VDI-Verlag, Düsseldorf, p. 249-264. (in German)

[68] Biček, M., Gotovac, G., Miljavec, D., Zupan, S. (2013). Hub bearing loading and lifetime for in-wheel motors. DVM Tag 2013: Sicherheit im Elektromobilitat, p. 79-88. (in German)

[69] Weng, Z.Y., Fang, L.K., Huang, D.J., Lu, B. (2011). Study on life estimation of car hub bearing. Applied Mechanics and Materials, vol. 58-60, p. 319-325, D0l:10.4028/www. scientific.net/AMM.58-60.319.

[70] Seker, S. (2000). Determination of air-gap eccentricity in electric motors using coherence analysis. IEEE Power Engineering Review, vol. 20, no. 7, p. 48-50, DOl:10.1109/39.850436.

[71] Murotani. C. (2005). Bearing \& seal technologies for electric vehicle eliica project. Koyo Engineering Journal English Edition, No. 168E, p. 35-38.

[72] Chaithongsuk, S. (2006). Design and Construction of Permanent Magnet Synchronous Motor. King Mongkut's Institute of Technology, Bangkok.

[73] ISO 2631-1:1997. (1997). Mechanical Vibration and Shock - Evaluation of Human Exposure to Whole-Body Vibration Part 1: General requirements. International Organization for Standardization, Geneva.

[74] Johansson, A., Nilsson, L. (2006). Evaluation of Discomfort Using Real-Time Measurements of Whole Body Vibration and Seat Pressure Distribution While Driving Trucks. Lulea University of Technology, Lulea.

[75] Krishnasamy, P., Jayaraj, J., Dennie. J. (2013). Experimental investigation on road vehicle active suspension. Strojniški vestnik - Journal of Mechanical Engineering, vol. 59, no. 10, p. 620-625, D0l:10.5545/sv-jme.2012.925.

[76] Fraunhofer Institute for manufacturing Technology and Advanced Materials IFAM (2012). Fraunhofer IFAM - Annual Report 2011/2012. Fraunhofer IFAM, Bremen. 
[77] Rezig, A., Mekideche, M.R., Djerdir, A. (2010). Effect of rotor eccentricity faults on noise generation in PMSM. Progress in Electromagnetics Research C, vol. 15, p. 117-132, DOI:10.2528/PIERC10071001.

[78] Nasser, M.A. (2004). Modal based predictive design and analysis of electric motors. IMAC-XXII Conference \& Exposition on Structural Dynamics, p. 142-166.

[79] ISO 281:2007(E). Bearing Life Standard. International Organization for Standardization. Geneva.

[80] Inman, D.J. (2006). Vibration with Control. John Wiley \& Sons, New York, DOI:10.1002/0470010533.

[81] Palmer, B., Lee, Y.L., Polehna, D. (2009). Fatigue damage spectrum calculation based on vibration specifications, International Auto Body Congress, p. 1-33.

[82] Sakashita, Y. (2002). Noise and vibration analysis technology of electric motors. JMAG Users Conference, p. 34-56.

[83] Choi, K.K., Kim, N.-H. (2005). Structural Sensitivity Analysis and Optimization 1: Linear Systems. Springer, New York.

[84] Choi, K.K., Kim, N.-H. (2006). Structural Sensitivity Analysis and Optimization 2: Nonlinear Systems and Applications. Springer, New York.
[85] Yin, D. (2010). Method research of establishing load spectrum on durability test of the car hub bearing. International Conference of Mechanical Automation and Control Engineering, vol. 2, no. 1, p. 3132-3136.

[86] Weissner, G. (2013). Wheel hub drive: system testing on test rig in vehicle. DVM Tag 2013: Sicherheit im Elektromobilitat, p. 69-77. (in German)

[87] Bhowmik, P.S., Pradhan, S., Prakash, M. (2013). Fault diagnostics and monitoring methods of induction motors. International Journal of Applied Control, Electrical and Electronics Engineering, vol. 1, no. 1, p. 1-18.

[88] Ergin, S., Uzuntas, A., Gulmezoglu, M.B. (2012). Detection of stator, bearing and rotor faults in induction motors. Procedia Engineering, vol. 30, p. 1103-1109, Dol:10.1016/j. proeng.2012.01.969.

[89] Heyes, A.M. (1998). Automotive component failures. Engineering Failure Analysis, vol. 5, no. 2, p. 129-144, DOI:10.1016/S1350-6307(98)00010-7. 